\title{
Análise econômica financeira do emprego de cobertura vegetada em edifícios públicos
}

\section{Financial economic analysis of the use of vegetated roofs in public buildings}

\author{
Renata Vieira Kock Graduanda em Ciências Contábeis. Universidade Federal de Santa Catarina (UFSC) - Brasil. \\ renatakock@gmail.com \\ Viviane Theiss Doutora em Contabilidade. Universidade Federal de Santa Catarina (UFSC) - Brasil. \\ viviane.theiss@ufsc.br \\ Sergio Parizotto Filho Mestre em Engenharia Civil. Instituto Federal de Santa Catarina (IFSC) - Brasil. \\ sergio.parizotto@ifsc.edu.br
}

\section{RESUMO}

O desempenho térmico de uma edificação é relacionado diretamente aos materiais que é composto. A cobertura é a parte da envoltória que está mais exposta à radiação solar direta e com isso tem forte influência sobre a transferência de calor aos ambientes internos. A cobertura vegetada é sugerida como tecnologia para o auxílio da redução do consumo energético em edificações. Esta pesquisa refere-se a um estudo de caso hipotético sobre a aplicabilidade de um sistema de cobertura vegetada em um edifício de uso educacional público (laboratórios de informática) na cidade de Florianópolis, no período de um ano letivo. Para atingir os objetivos deste estudo foi realizada simulação numérica, em 3 situações propostas, através do programa EnergyPlus, orçamento de materiais através do SINAPI, determinação de uma taxa mínima de atratividade e aplicação de técnicas de análise de viabilidade econômico financeiras (VPL, Payback e TIR). A máxima economia com o consumo de energia elétrica para resfriamento foi de $8,7 \%$. Como resultado verificou-se que o orçamento da cobertura vegetada tem seu custo aproximadamente três vezes maior que o da cobertura convencional de fibrocimento. Para todas as situações obteve-se Valor Presente Líquido (VPL) negativo e a Taxa Interna de Retorno (TIR) não superou a Taxa Mínima de Atratividade (TMA) determinada. Na situação com melhor desempenho térmico, para que o investimento inicial fosse completamente recuperado, ou seja, ter seu VPL zerado na data limite, ainda faltaria recuperar $27 \%$ do investimento.

Palavras-chave: Viabilidade Econômica Financeira. Telhado verde. Desempenho Térmico.

\begin{abstract}
The thermal performance of a building is directly related to the materials it is composed of. The roof is the part of the envelope that is most exposed to direct solar radiation and therefore has a strong influence on the transfer of heat to indoor environments. The vegetated roofs are suggested as a technology to help reduce energy consumption in buildings. This research refers to a hypothetical case study on the applicability of a vegetated roof system in a building for public educational use (computer labs) in the city of Florianópolis, in the period of an academic year. In order to achieve the objectives of this study, numerical simulation was carried out in 3 proposed situations, through the EnergyPlus program, materials budget through SINAPI, determination of a minimum attractiveness rate and application of financial economic viability analysis techniques (NPV, Payback and IRR). The maximum savings with electricity consumption for cooling was $8.7 \%$. As a result, it was found that the budget for a vegetative roof has a cost approximately three times greater than that of conventional fiber cement roof. For all situations, negative Net Present Value (NPVs) were obtained and the Internal Rate of Return (IRR) did not exceed the determined Minimum Attractiveness Rate of Return (MARR). In the situation with better thermal performance, for the initial investment to be completely recovered, that is, to have its NPV zeroed by the deadline, $27 \%$ of the investment would still have to be recovered.
\end{abstract}

Keywords: Financial Economic Viability. Green Roof. Thermal Performance. 


\section{INTRODUÇÃO}

O tripé da sustentabilidade é baseado sob aspectos, sociais, ambientais e econômicos. A integração da sustentabilidade ambiental ao contexto econômico muitas vezes é vista como um empecilho ao crescimento. A preocupação ambiental necessita de alicerces sólidos para orientar de forma autônoma decisões de políticas públicas, econômicas e sociais (IPEA, 2010).

As Organizações das Nações Unidas (2015), em seu sétimo objetivo de Desenvolvimento Sustentável pretende, até 2030, dobrar a taxa global de melhoria de eficiência energética. Segundo a Eletrobrás (2005), cerca de $48 \%$ do consumo de energia elétrica nas instituições públicas está relacionado ao uso de sistema de condicionamento de ar. Dentre as possibilidades, Ferraz (2012) descreve para o uso da cobertura vegetada como alternativa, que pode auxiliar no controle térmico da edificação e assim reduzir o consumo energético referente ao uso de ar condicionado.

O governo, através de legislação é capaz de incentivar a utilização de materiais sustentáveis na construção civil e assim aumentar o número de construções em moldes estabelecidos (DELBONO; RODRIGUES, 2014). Em Recife, a Lei 18.112 de 2015 já torna obrigatória a instalação de "telhados verdes" para melhoria da qualidade ambiental das edificações. Em Salvador, o Decreto 25.899 de 2015 institui o programa "IPTU VERDE" onde a utilização de cobertura vegetada configura um quesito para desconto no valor do IPTU.

Desde 2014, todos os projetos e construções de edificação pública federal devem, obrigatoriamente, obter a Etiqueta Nacional de Conservação de Energia - ENCE nível "A", conforme Instrução Normativa MPOG/SLTI no 02, de 04 de junho de 2014. O Regulamento Técnico da Qualidade para o Nível de Eficiência Energética de Edificações Comerciais, de Serviços e Públicas - RTQ-C, sugere como uma das opções obrigatórias quanto a absorbância da superfície a escolha de teto jardim para obter a etiqueta nível " $\mathrm{A}$ ".

Conforme o Relatório Global de Edifícios e Construções (GABC, 2019), em 2018 o setor da construção civil foi responsável por consumir $36 \%$ da energia mundial e pela emissão de $39 \%$ de dióxido de carbono na atmosfera. No Brasil, em 2018, aproximadamente $42,3 \%$ do consumo de energia elétrica foi por meio do uso em edificações (BALANÇO ENERGÉTICO ANUAL, 2018). A forma mais barata de gerar economia com energia nas edificações é a utilização de sistemas energeticamente eficientes. Além disso, a implantação de tecnologias sustentáveis nas edificações é a "alternativa mais barata e mais efetiva para redução das emissões de CO2" (AGOPYAN; JOHN, 2011, p. 42). Conforme Lamberts, Dutra e Pereira (2014, p. 5), "um edifício é mais eficiente energeticamente que outro quando proporciona as mesmas condições ambientais com menor consumo de energia".

\section{PROBLEMA E OBJETIVO}

Liz (2016) apresenta que as coberturas vegetadas são uma contribuição efetiva para melhorar o desempenho térmico da cobertura para o clima de Florianópolis. Seu estudo propõe auxílio a elaboração de normas e regulamentos municipais que tem como objetivo incluir coberturas vegetadas em iniciativas de sustentabilidade nas edificações.

O sistema construtivo de uma edificação é relacionado diretamente ao seu desempenho térmico. Devido à maior área de troca de calor com o ambiente e maior exposição à radiação solar a cobertura apresenta um consumo de energia elétrica com resfriamento superior a outros pavimentos para manter o ambiente interno em conforto térmico (COSTA; LIMA, 2017). O crescimento do consumo energético é uma preocupação que atinge a sociedade e com isso as tecnologias de construção sustentáveis estão ganhando espaço no mercado por uma questão de necessidade. A cobertura vegetada é uma opção disponível que auxilia o desempenho térmico da edificação além de melhorar em diferentes aspectos seu entorno (DIAS, 2016).

Tendo por base as vantagens sócio ambientais que uma cobertura vegetada pode proporcionar quando comparada a um telhado convencional, a questão problema que norteia este artigo é: Qual a viabilidade econômico financeira do uso de coberturas vegetadas para uma edificação pública educacional em Florianópolis? Para responder a esta questão, o objetivo deste trabalho é verificar a viabilidade econômica e financeira entre o uso de cobertura vegetada e convencional para uma edificação educacional pública em Florianópolis. 
O estudo foi realizado através de simulação computacional de um modelo criado com layout do último andar de uma instituição educacional com 6 salas de laboratório de informática para o período de um ano letivo em horário integral. Os custos de ambos os sistemas construtivos das coberturas foram orçados através do Sistema Nacional de Pesquisa de Custo e Índices da Construção Civil - SINAPI.

Para a análise da viabilidade econômica financeira foi determinada uma Taxa Mínima de Atratividade (TMA) e aplicou-se cálculos do Valor Presente Líquido (VPL), Taxa Interna de Retorno (TIR) e Payback para auxiliar na tomada de decisão e na possibilidade de constituir um incentivo adicional a escolha desta tecnologia. Para Souza Júnior et al. (2019), tais métodos de investimento permitem uma avaliação econômica e financeira entre o investimento desejado e a economia projetada e assim evidenciar o retorno do projeto escolhido.

\section{FUNDAMENTAÇÃO TEÓRICA}

Este capítulo aborda os conceitos fundamentais para a análise de viabilidade econômica financeira e conceitua cobertura vegetada. Segundo NBR 15.575-5 (ABNT, 2013), telhado é um elemento constituído de telhas e seus subsistemas. Como o sistema ajardinado não levará telhas, será utilizado o termo cobertura vegetada durante o decorrer deste trabalho.

\subsection{Viabilidade econômico financeira}

Uma atividade sustentável, além de ecologicamente correta e socialmente justa, precisa ser economicamente viável. O produto desenvolvido requer preços competitivos, porém não deve gerar desequilíbrio nos ecossistemas e tampouco lucrar em cima da exploração de mão de obra (LUCHEZZI, 2017). Para Yemal, Teixeira e Naas (2011), as empresas utilizam a questão ambiental de forma a melhorar seus processos e ao mesmo tempo visarem maior lucro. O crescimento econômico associado a conservação ambiental insere o desenvolvimento sustentável no contexto de mudanças sociais, culturais e políticas, desta forma, governo e empresas buscam agir em consonância com o meio ambiente e bem estar social (SANTOS, 2009).

Em um estudo de viabilidade econômico financeira, busca-se analisar a aplicabilidade de um projeto, por meio de levantamento dos custos, de uma TMA e modelos determinísticos como o Payback, o VPL e a TIR para avaliar oportunidades de investimento (BORDEAUX-RÊGO et al., 2010).

No que tange a parte de custos, referente ao orçamento, utiliza-se o SINAPI. Neste sistema, o Instituto Brasileiro de Geografia e Estatística - IBGE, pesquisa mensalmente preços de equipamentos, materiais de construção e salários das categorias correspondentes nas 27 capitais brasileiras. É de competência da Caixa Econômica Federal, a relação de serviços e especificações das composições de custo. Com os quantitativos de materiais, da mão de obra e do tempo necessário para a realização dos serviços, é possível, de acordo com os preços de insumos e salário, fazer o cálculo dos custos unitários de execução dos serviços (BAETA, 2012).

A TMA refere-se ao custo de financiamento ou custo de oportunidade, que, neste caso é a rentabilidade gerada por outro tipo de investimento, sendo ele próprio ou terceiros (FREZATTI, 2008).

Um dos métodos utilizados para a análise de projeto é o Payback, que pode ser simples ou descontado e serve para saber em quanto tempo o capital investido será retornado. O Payback simples consiste no quociente entre o investimento inicial e o ganho do período (ABEL et al., 2019). Quem resolve investir estipula um determinado período que considera aceitável e este servirá para a análise de viabilidade do projeto. $\mathrm{O}$ Payback descontado consiste em igualar os fluxos de caixa futuros, descontados a uma TMA e trazidos a data zero, ao investimento inicial, o momento em que isto ocorre é o tempo de recuperação do investimento inicial (BORDEAUX-RÊGO et al., 2010).

O fluxo de caixa descontado depende da projeção dos fluxos, do valor residual estimado e da taxa de desconto determinada. Esta é uma etapa essencial do orçamento de capital, ele se subdivide em investimento inicial, que corresponde a saída de caixa substancial no instante zero, e fase de operação do projeto, onde os fluxos de caixa líquidos anuais são gerados (BORDEAUX-RÊGO et al., 2010).

O VPL é obtido pela subtração dos fluxos de caixa, descontados a uma taxa de custo de oportunidade da empresa, ao investimento inicial do projeto (FREZATTI, 2008). Esta estratégia é em função do valor investido, 
do fluxo de caixa gerado, do tempo em que ocorre o fluxo de caixa e o risco associado. Além de VPL, ele também é chamado de método do fluxo de caixa descontado e é dado pela Equação 1:

$V P L=-I+\sum_{t=1}^{n} \frac{F C_{t}}{(1+r)^{t}}+\frac{V R}{(1+r)^{n}}$

Onde:

I = investimento inicial,

$F C_{t}=$ é o fluxo de caixa na data " $\mathrm{t}$ "

$\mathrm{t}=$ período de tempo

$r=$ custo de capital definido pela empresa

$\mathrm{VR}=$ valor residual do projeto ao final do período de análise.

Para a tomada de decisão sobre o investimento deve-se verificar se o VPL é positivo, negativo ou nulo. Se este for positivo tem-se que na data zero os fluxos de caixa futuros descontados a uma taxa mínima de atratividade, tem valor presente maior do que o capital investido. Se isto acontece o capital investido é recuperado e a remuneração do investimento ultrapassa a taxa de atratividade da empresa (BORDEAUX-RÊGO et al., 2010). Para Kreuz et al. (2004), o resultado do VPL é útil, porém necessita de indicadores complementares para dar suporte a mensuração do retorno obtido.

Outra técnica de análise a ser empregada é a TIR, taxa de desconto que torna o VPL nulo, ou seja, igual ao valor presente das entradas de caixa ao investimento inicial do projeto e é utilizada como forma de comparação com a taxa mínima de atratividade (FREZATTI, 2008). Quando a taxa requerida TMA for maior que a TIR o VPL do projeto é negativo e indica que o mesmo não deve ser aceito e quando a TIR for maior que a TMA acontece o contrário. O cálculo desta taxa, quando feito para mais de 4 (quatro) períodos, é realizado através de procedimento automático da função financeira TIR do Excel (LAPPONI, 2007).

O Quadro 1 demonstra estudos de viabilidade econômico financeira e seus principais métodos empregados visando validar aplicabilidade deles.

Quadro 1- Pesquisas sobre Viabilidade Econômico Financeira

\begin{tabular}{|c|c|c|c|}
\hline Objetivo & Métodos & Resultados & Referência \\
\hline $\begin{array}{l}\text { Analisar a viabilidade econômico- } \\
\text { financeira da energia solar fotovoltaica em uma } \\
\text { Instituição de Ensino Superior do Sul do Brasil. }\end{array}$ & $\begin{array}{l}\text { VPL, TIR, } \\
\text { Payback }\end{array}$ & Viável & $\begin{array}{c}\text { (DASSI et al., } \\
\text { 2015). }\end{array}$ \\
\hline $\begin{array}{l}\text { Analisar a viabilidade econômica na } \\
\text { geração de energia elétrica através do biogás, } \\
\text { em uma propriedade de suinocultura } \\
\text { localizada na região norte do RS. }\end{array}$ & $\begin{array}{l}\text { VPL, TIR, } \\
\text { Payback }\end{array}$ & Viável & $\begin{array}{l}\text { (PASSAGLIA; } \\
\text { SANTO; GUIDINI, } \\
\text { 2019). }\end{array}$ \\
\hline $\begin{array}{l}\text { Mensurar a viabilidade econômica de } \\
\text { um sistema aquapônico de pequena escala, } \\
\text { exclusivamente para agricultores familiares. }\end{array}$ & $\begin{array}{l}\text { VPL, TIR, TMA, } \\
\text { VAUE, Payback, } \\
\text { IL, TIRM }\end{array}$ & $\begin{array}{l}\text { Inviável. Se torna } \\
\text { viável quando são } \\
\text { retirados custo com } \\
\text { terra e mão de obra. }\end{array}$ & $\begin{array}{c}\text { (MARTINELLI et al., } \\
\text { 2019). }\end{array}$ \\
\hline $\begin{array}{l}\text { Verificar a existência de viabilidade } \\
\text { econômica para a geração de energia elétrica a } \\
\text { partir de um sistema solar fotovoltaico, visando } \\
\text { a redução dos custos com a energia elétrica } \\
\text { para famílias de classe baixa, média e alta } \\
\text { localizadas no município do Sinop/MT. }\end{array}$ & $\begin{array}{c}\text { VPL, TIR, } \\
\text { Payback, VPLA, } \\
\text { B/C, IR }\end{array}$ & $\begin{array}{l}\text { Viável para classe } \\
\text { alta e inviável para } \\
\text { classe média e } \\
\text { baixa. }\end{array}$ & $\begin{array}{c}\text { (DALFOVO et al., } \\
\text { 2019). }\end{array}$ \\
\hline $\begin{array}{l}\text { Analisar a viabilidade econômica e } \\
\text { financeira da instalação de um projeto de } \\
\text { geração de energia solar fotovoltaica em } \\
\text { Organizações Militares (OMs) do Exército } \\
\text { Brasileiro na cidade de Santa Maria/RS. }\end{array}$ & $\begin{array}{l}\text { VPL, TIR, } \\
\text { Payback }\end{array}$ & $\begin{array}{l}\text { Viável para } \\
\text { situações de alto } \\
\text { consumo e inviável } \\
\text { para o projeto de } \\
\text { baixo consumo. }\end{array}$ & $\begin{array}{c}\text { (SOUZA JÚNIOR et } \\
\text { al., 2019). }\end{array}$ \\
\hline $\begin{array}{l}\text { Analisar a viabilidade econômico- } \\
\text { financeira de um projeto de Energia Solar } \\
\text { Fotovoltaica do Hotel Praiano (Tapes -RS). }\end{array}$ & $\begin{array}{l}\text { VPL, TIR, } \\
\text { Payback }\end{array}$ & Viável & (ABEL et al., 2019). \\
\hline
\end{tabular}

Fonte: elaborado pelos autores (2020). 
Todos os estudos apresentados no Quadro 1 tem como objetivo verificar a viabilidade econômica financeira de um investimento sustentável, quanto aos métodos utilizados eles tem em comum o VPL, TIR e Payback. De modo geral, estes tipos de estudos possuem alto investimento inicial, associação direta do consumo de energia e produção pelo sistema. Nenhuma das pesquisas explorou o uso de coberturas vegetadas, neste caso, a associação torna-se um pouco mais complexa devido aos diferentes benefícios e possibilidades de mensuração.

\subsection{Cobertura vegetada}

Coberturas vegetadas são caracterizadas por conter uma membrana a prova d'água, uma camada de material drenante, camada filtrante, faixa de solo e, por fim, a vegetação (SAADATIAN et al., 2013). O uso desta técnica, no Brasil, teve início em 1930, no prédio do Ministério da Saúde e Educação no Rio de Janeiro, pelo arquiteto Lucio Costa (MACHADO et al., 2017).

Segundo a literatura, o uso deste tipo de cobertura traz benefícios em diferentes áreas. Com potencial para auxiliar na diminuição de ilhas de calor (RAZZAGHMANESH; BEECHAM; SALEMI, 2015). Mitigar os problemas com a drenagem urbana, contribuir para a redução da poluição difusa e auxiliar na melhoria da qualidade dos cursos d'água a que a rede pluvial direciona o escoamento (KLEIN, 2017). Além disto, as coberturas vegetadas demonstram melhores performances quanto aos índices de conteúdo energético e emissão de dióxido de carbono, apresentando-se menos poluente inclusive em sua fase pré-operacional (PEREIRA, 2014).

Na cidade de Sydney, em 2014, foi criado um plano de implementação de políticas sobre paredes e coberturas vegetadas com objetivo de aumentar o número e a qualidade das coberturas e paredes vegetadas. Benefícios como aumento no tempo de vida útil da parte estrutural da cobertura, redução de ruídos, preservação da biodiversidade, redução de ilhas de calor e conforto térmico. Neste contexto, o sistema de coberturas vegetadas é uma das tecnologias que providencia benefícios sociais, econômicos e ambientais (SYDNEY, 2014).

Em relação ao conforto térmico, essa tecnologia permite que o ambiente seja climatizado naturalmente. No verão minimiza o aquecimento e durante o inverno neutraliza o frio através do calor acumulado durante o dia (MINGUET, 2016). Kumar e Mahalle (2016) encontraram uma redução de $4,4^{\circ} \mathrm{C}$ na temperatura interna do ambiente com utilização de cobertura vegetada e afirmaram que em climas quentes esta tecnologia contribui para o conforto humano e minimiza os gastos com condicionamento de ar.

\section{METODOLOGIA}

Esta pesquisa refere-se a um estudo de caso hipotético onde foi analisado a aplicabilidade de um sistema de cobertura vegetada para um edifício com características de uso educacional público (laboratórios de informática) para a cidade de Florianópolis no período de um ano letivo.

Para atingir os objetivos deste estudo foi realizada simulação numérica através do programa EnergyPlus, cuja utilização é indicada pelo Regulamento Técnico da Qualidade para o Nível de Eficiência Energética de Edificações Comerciais, de Serviços e Públicas (2010), para este tipo de simulação. A metodologia de cálculo sobre coberturas vegetadas dentro do EnergyPlus foi conforme o modelo EcoRoof de Sailor (2008), através do material Roofvegetation.

\subsection{Modelo computacional}

O modelo foi desenvolvido de modo a representar o último pavimento de um edifício para uso educacional público. O modelo é formado por 6 salas de aula, considerando-se 30 alunos por sala e utilização como laboratório de projetos auxiliado por computador, suas dimensões horizontais são de $10 \mathrm{~m} \times 6 \mathrm{~m}$, e altura de $2,8 \mathrm{~m}$ e um corredor central, como demonstrado na planta baixa e modelo, na Figura 1. A área de cobertura 
totaliza $450 \mathrm{~m}^{2}$ e toda sala possui uma área de abertura de $10,4 \mathrm{~m}^{2}$. Cada ambiente representa uma zona térmica no modelo computacional dentro do programa EnergyPlus.

Figura 1 - Planta baixa e modelo

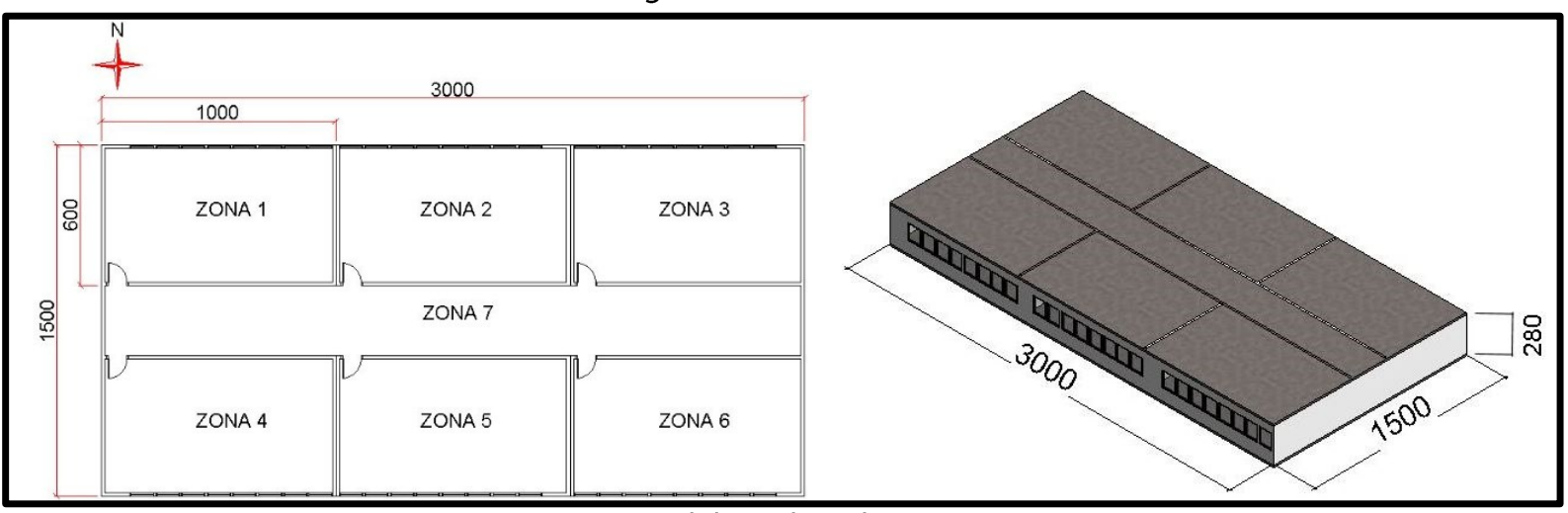

Fonte: Elaborado pelos autores (2019).

A configuração do modelo para laje inferior é adiabática, a vedação vertical com bloco cerâmico e composição com transmitância térmica inferior a $3,7 \mathrm{~W} / \mathrm{m}^{2} \mathrm{~K}$, sendo esta a máxima exigida pelo RTQ-C para a localização de Florianópolis, zona bioclimática 3, conforme NBR 15220-2 (ABNT, 2005). O modelo foi simulado com o arquivo bioclimático TRY, da cidade de Florianópolis, cedido pelo Laboratório de Eficiência Energética em Edificações da UFSC. Para a leitura da precipitação, utilizou-se o arquivo do repositório de dados climáticos gratuitos para construção de simulação de desempenho (CLIMATE ONE BUILDING, 2019).

A carga térmica interna foi estabelecida pela densidade de potência de iluminação, quantidade de pessoas (30 alunos +1 professor) e um computador por pessoa. A simulação foi realizada no intervalo de um ano letivo, com horário institucional educacional em período integral (manhã, tarde e noite).

Foi utilizado um sistema de ar do tipo SPLIT, com adoção de coeficiente de performance mínimo de 3,24 , conforme tabela do INMETRO para etiqueta nível A. O setpoint para resfriamento foi de 23 graus centígrados, temperatura que está dentro dos limites de sensação de conforto segundo NBR 16.401-2 (ABNT, 2008). A partir desde sistema o software permite relatórios de saída com a carga térmica necessária para resfriamento bem como o consumo, em $\mathrm{kWh}$, de energia elétrica.

Foram feitas simulações com a cobertura vegetada e a cobertura convencional (telhado de fibrocimento), onde a cobertura padrão teve seu consumo energético com ar condicionado utilizado para resfriamento comparado com três situações de cobertura vegetada. Situação $A$, coberta totalmente por cobertura vegetada; Situação B, onde as zonas 4, 5, 6 e 7 são vegetadas e as zonas 1, 2 e 3 são padrão; e, Situação $C$, onde somente a zona 7 é vegetada e as outras são convencionais. Tais situações foram propostas de modo a conhecer melhor o desempenho térmico da cobertura vegetada em diferentes posições solares, carga interna, área da fachada exposta e suas consequências na economia de energia com uso de condicionamento de ar. A zona central, 7, foi escolhida por ter menor área de contato com o exterior e carga térmica interna reduzida. Na situação B, além da 7, as zonas 4, 5 e 6, que estão representadas como vegetadas, foram selecionadas pois possuem sua fachada voltada para o sul, onde a incidência solar é de menor intensidade.

Ambas as coberturas são compostas por uma laje de concreto maciça com espessura de $10 \mathrm{~cm}$. Acima da laje a cobertura convencional possui uma câmara de ar e telhas de fibrocimento na espessura de $8 \mathrm{~mm}$, suas propriedades térmicas bem como a da laje são conforme NBR 15.220. A sequência das camadas da cobertura vegetada logo após a laje é: membrana de impermeabilização (I), camada drenante (D), camada filtrante (F), substrato vegetal com espessura de $10 \mathrm{~cm}$ e a vegetação em si. As propriedades térmicas das camadas I, D e F foram retiradas de pesquisas por Capozzoli, Gorrino e Corrado (2013), e para características específicas da vegetação por Dias (2016). 


\subsection{Análise econômica e financeira}

A análise econômica e financeira foi feita por meio de levantamento de custo dos materiais das coberturas propostas, custo do consumo com energia elétrica para resfriamento, determinação de TMA calculado fluxo de caixa descontado, comparado o VPL, TIR e Payback simples e descontado.

O valor do investimento inicial, fluxo de caixa na data 0 (zero), será a diferença do custo da cobertura vegetada para a cobertura de fibrocimento e os custos foram calculados com base no SINAPI e em pesquisas de empresas da área.

Para o valor dos fluxos anuais, os custos com o consumo de energia elétrica para resfriamento foram retirados do resultado das simulações, utilizada a classe Utility Cost, e foi possível separar os horários de pico e fora de pico, pois estes têm preços distintos e retirados da tabela de tarifas da CELESC (2019). Nos fluxos anuais é contabilizado o custo com manutenção das coberturas, onde o montante excedente que se refere a cobertura vegetada será contabilizado como despesa.

Para o cálculo do VPL, ou fluxo de caixa descontado, é necessário o emprego da TMA. Através dela há a possibilidade de considerar o valor do dinheiro no tempo. Por se tratar de uma obra pública, não há uma TMA de investimento no próprio capital, ou seja, não se tem um custo de capital próprio. Para este caso fo utilizada a taxa SELIC acumulada de 2019, 5,95\% ao ano, fornecida pela Receita Federal, analisados no período de janeiro a dezembro de 2019.

O período considerado no fluxo de caixa foi o prazo de vida útil da cobertura vegetada, como esta pode durar por tempo indeterminado, foi utilizado o tempo de vida correspondente a impermeabilização da laje. A NBR 15.575-1 (ABNT, 2013) apresenta que impermeabilizações de jardineiras, áreas externas com jardins e coberturas não utilizáveis tem prazo de vida útil máximo de 12 anos.

\section{DISCUSSÃO DOS RESULTADOS}

Este capítulo apresenta-se os valores de resultados das simulações paramétricas, quanto o consumo de energia elétrica para resfriamento, valor gasto com energia, custos da cobertura convencional de fibrocimento e da cobertura vegetada. Ao final, demonstra os resultados do VPL, TIR e Payback.

\subsection{Energia elétrica de resfriamento}

O consumo de energia elétrica com resfriamento foi fornecido em $\mathrm{kWh}$ através da variável de saída Cooling: Electricity dentro do programa EnergyPlus. O consumo de kWh por ano, para uso com resfriamento, da cobertura convencional foi de $41781 \mathrm{kWh}$, para as Situações $\mathrm{A}, \mathrm{B}$ e $\mathrm{C}$ das coberturas vegetada foram de $38940.1 \mathrm{kWh}, 39501.5 \mathrm{kWh}$ e $40361 \mathrm{kWh}$ respectivamente. A redução do consumo de energia do ar condicionado quando comparado por inteiro foi de 6,8\%, para as situações B e $C$, as diminuições foram de $5,5 \%$ e $3,4 \%$ respectivamente e se mostram superiores se comparadas a proporção de área vegetada. Isto ocorre em decorrência da carga térmica de resfriamento ter percentual diferente de atenuação entre as zonas, a zona 7 reduziu $25,7 \%$ seguida das zonas 5, 4 e 6, voltadas ao sul, com redução de 3,97\%, 4,47\% e 4,49\% respectivamente. As zonas 1, 2, 3, voltadas ao norte, onde há maior incidência solar, reduziram 2,78\%,2,03\% e $2,80 \%$ respectivamente.

Os valores das Tarifas foram retirados da CELESC, e foram enquadrados na categoria A4 - Demais Classes, Tarifa horária Verde conforme o Manual de tarifação da energia elétrica (PROCEL, 2011). O valor do kWh para o horário de ponta é de $R \$ 1,23251$ e fora de ponta $\mathrm{R} \$ 0,36506$ conforme tabela tarifa horária verde (CELESC, 2019). O consumo em cada situação está representado no 
Tabela 1. 
Tabela 1 - Consumo de Energia Elétrica para Resfriamento

\begin{tabular}{ccccc}
\hline \multirow{2}{*}{ Horário Consumo } & Convencional & \multicolumn{3}{c}{ Vegetadas } \\
\cline { 2 - 5 } & Fibrocimento & Situação A & Situação B & Situação C \\
\hline Ponta & $12.636,75$ & $11.136,28$ & $11.548,78$ & $12.041,33$ \\
Fora de Ponta & $11.509,66$ & $10.917,00$ & $10.999,77$ & $11.167,65$ \\
\hline TOTAL & $24.146,41$ & $22.053,28$ & $22.548,55$ & $23.208,98$ \\
\hline Economia Energia [R\$] & - & $2.093,13$ & $1.597,86$ & 937,43 \\
\hline Economia Energia [\%] & - & $8.7 \%$ & $6.6 \%$ & $3.9 \%$ \\
\hline
\end{tabular}

Fonte: Elaborado pelos autores (2019).

Se calculada porcentagem de economia proporcional a área de cobertura vegetada, a situação $C$ economizaria mais que o dobro da situação A. Devido a carga interna proposta para a zona 7 ser inferior as zonas que representam salas de aula e por possuir uma área inferior a exposição solar em suas fachadas.

\subsection{Custo cobertura convencional e vegetada}

O custo da cobertura convencional foi retirado do SINAPI. Para tal foi considerada a área da cobertura de $450 \mathrm{~m}^{2}$ e para cumeeira o comprimento da cobertura, 30 metros. O custo do material dividiu-se em madeiramento, telhamento e cumeeira. Foi retirado respectivamente dos itens 92566, 94210 e 94223 do catálogo de composições analíticas de 04/2019.

O custo com madeiramento foi de R\$9.003,95. O telhamento, dentro de sua composição escolhida no caderno técnico de composição para telhamento e serviços complementares para estrutura (SINAPI, 2019), permite a substituição do insumo 7194 para o 7198, ou seja, a telha de $6 \mathrm{~mm}$ foi trocada na composição com o mesmo coeficiente pela telha de $8 \mathrm{~mm}$. Totalizando um custo de $\mathrm{R} \$ 19.903,62$. A cumeeira, retirada do item 94223, Cumeeira para telha de fibrocimento ondulada e $=6 \mathrm{~mm}$, incluso acessórios de fixação e içamento af_06/2016, não teve equiparação para a espessura de $8 \mathrm{~mm}$, o que pode ter deixado este item um pouco abaixo do valor real. Seu custo foi orçado em $\mathrm{R} \$ 1.2710,31$. O custo total de implantação da cobertura convencional foi de $\mathrm{R} \$ 30.177,88$, equivalente a $\mathrm{R} \$ 67,06$ por $\mathrm{m}^{2}$.

No sistema de cobertura vegetada, primeiramente foi necessária a impermeabilização da laje, cujo custo foi baseado na área da cobertura. Feito na composição 98546, impermeabilização de superfície com manta asfáltica, uma camada, inclusive aplicação de primer asfáltico, e= $3 \mathrm{~mm}$, af_06/2018, do caderno de impermeabilização do SINAPI. O orçamento resultou em um montante de R\$ 30.961,70.

Após a impermeabilização é executada a camada de drenagem. O custo desta parte do sistema foi baseado no orçamento em empresa da área para a parte do material e no SINAPI para a mão de obra. A empresa pesquisada ofereceu uma geomembrana drenante em rolos de $40 \mathrm{~m}^{2}$, ou seja, a metragem total passou a ser de $480 \mathrm{~m}^{2}$, o que já inclui perdas com o material, pois a cobertura possui $30 \mathrm{~m}^{2}$ a menos. $O$ valor do $\mathrm{m}^{2}$ da manta custa $\mathrm{R} \$ 48,70$ resultando em um total de $\mathrm{R} \$ 23.376,00$. Esta mesma empresa não oferece mão de obra, porém informou que não necessita de profissional especializado para instalação, então, optou-se por utilizar uma composição do SINAPI, que também trabalhe com geomembranas para parametrizar o valor da mão de obra. A composição foi a de número 74033/1 do catálogo de composições analíticas do SINAPI de $04 / 2019$ e resultou em um valor de mão de obra de $\mathrm{R} \$ 3.502,80$. O custo total com a camada drenante foi de $\mathrm{R} \$ 26.878,00$.

A camada superior a drenagem é a filtrante, para tal foi considerado uma manta geotêxtil. Este custo foi retirado por completo do SINAPI na composição do item 83739, para a área de $450 \mathrm{~m}^{2} \mathrm{R} \$ 2.031,21$.

A cobertura vegetada possui $10 \mathrm{~cm}$ de espessura em sua camada de substrato vegetal, e esta localizase acima da filtrante. Seu orçamento foi uma adaptação no SINAPI. O caderno de preços de insumos 04/2019 contém o item "Terra Vegetal (granel)" que corresponde ao número 7253 e tem seu valor ofertado por $\mathrm{m}^{3}$. Seu coeficiente foi calculado verificando quanto de terra iria por $\mathrm{m}^{2}$ para esta espessura, ou seja, $0,1 \mathrm{~m}^{3}$ de terra 
por $\mathrm{m}^{2}$. Para o valor da mão de obra foi escolhido o item 85422 que diz respeito ao preparo manual de terreno. A adaptação da composição está demonstrada no Tabela 2 abaixo e tem como valor total $R \$ 8.087,85$.

Tabela 2 - Custo Camada Substrato Vegetal

\begin{tabular}{|c|c|c|c|c|c|c|c|}
\hline Classe/Tipo & Código & Descrição & Un. & Coef. & Preço & Preço & Preço \\
\hline Não aferida & 85422 & $\begin{array}{l}\text { Preparo manual de terreno s/ } \\
\text { raspagem superficial }\end{array}$ & $\mathrm{m}^{2}$ & - & Uni & $\mathrm{m}^{2}$ & $\begin{array}{c}\text { Total } \\
{\left[450 \mathrm{~m}^{2}\right]}\end{array}$ \\
\hline Composição & 88316 & $\begin{array}{c}\text { servente com encargos } \\
\text { complementares }\end{array}$ & $\mathrm{H}$ & 0,4 & 16,54 & 6,62 & $2.977,2$ \\
\hline Insumo (fora composição) & 7253 & terra vegetal (granel) & $\mathrm{m}^{3}$ & 0,1 & 113,57 & 11,36 & $5.110,65$ \\
\hline
\end{tabular}

Fonte: Adaptado do SINAPI (2019).

A última camada do sistema é a própria vegetação, esta composição foi retirada do item 98505 que está no caderno de paisagismo do SINAPI. Seu orçamento está representado na Tabela 33 e resulta num valor total de $\mathrm{R} \$ 15.580,84$.

Tabela 3 - Custo Camada Vegetação

\begin{tabular}{|c|c|c|c|c|c|c|c|}
\hline Classe/Tipo & Código & Descrição & Un. & Coef. & Preço & Preço & Preço \\
\hline $\begin{array}{c}\text { 02, urba, pais, } \\
003 / 01\end{array}$ & 98505 & $\begin{array}{c}\text { Plantio de forração, } \\
\text { af_05/2018 }\end{array}$ & $\mathrm{m}^{2}$ & - & Uni & $\mathrm{m}^{2}$ & $\begin{array}{c}\text { Total } \\
{\left[450 \mathrm{~m}^{2}\right]}\end{array}$ \\
\hline Insumo & 360 & $\begin{array}{c}\text { Muda de rasteira/forração, } \\
\text { amendoim rasteiro/onze } \\
\text { horas/azulzinha/impatiens ou } \\
\text { equivalente da região }\end{array}$ & UN & 25.00 & 1,2 & 30,00 & $13.500,00$ \\
\hline Composição & 88316 & $\begin{array}{c}\text { servente com encargos } \\
\text { complementares }\end{array}$ & $\mathrm{H}$ & 0,211 & 16,54 & 3,49 & $1.570,47$ \\
\hline Composição & 88441 & $\begin{array}{c}\text { jardineiro com encargos } \\
\text { complementares }\end{array}$ & $\mathrm{H}$ & 0,0528 & 21,48 & 1,13 & 510,36 \\
\hline & & Total & & & & & $15.580,84$ \\
\hline
\end{tabular}

Fonte: Adaptado do SINAPI (2019).

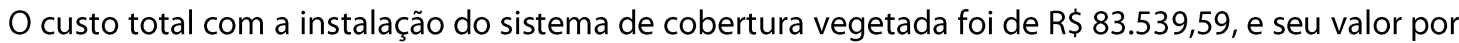
$\mathrm{m}^{2}$ foi de $\mathrm{R} \$ 185,64$.

\subsection{Análise de viabilidade econômico financeira}

Os valores dos desembolsos iniciais do investimento configuram-se como o excedente, do que já seria despendido caso se optasse pela escolha da cobertura de fibrocimento. A Tabela 4 demonstra os fluxos de caixa na data zero para as três situações propostas, Situação A (comparação sobre a cobertura completa, 450 $\mathrm{m}^{2}$ ), Situação $B$ (cobertura vegetada se encontra nas zonas 4, 5, 6 e 7, $270 \mathrm{~m}^{2}$ ) e a Situação $C$ (cobertura vegetada corresponde ao corredor, zona $7,90 \mathrm{~m}^{2}$ ).

Tabela 4 - Investimento Inicial

\begin{tabular}{cccc}
\hline & Situação A & Situação B & Situação C \\
\hline Cobertura Vegetada & $83.539,59$ & $50.123,76$ & $16.707,92$ \\
Cobertura Convencional & $30.177,88$ & $18.106,73$ & $6.035,57$ \\
\hline Desembolso Fluxo 0 & $(53.361,72)$ & $(32.017,03)$ & $(10.672,34)$ \\
\hline
\end{tabular}

Fonte: elaborada pelos autores (2019). 
Para os fluxos anuais projetados além da energia despendida com resfriamento é contabilizado a manutenção dos tipos de cobertura. Conforme Silveira, Marinoski e Lamberts (2012), as telhas de fibrocimento sujas podem ter sua temperatura superficial aumentada em cerca de $6^{\circ} \mathrm{C}$ e ter uma piora em seu desempenho térmico, o que evidencia a necessidade de manutenção, estipulando-se, portanto, uma manutenção anual.

A manutenção feita nas telhas de fibrocimento foi considerada como a limpeza das mesmas, o custo com limpeza do telhado foi retirado do SINAPI através da composição 99814 e foi contabilizado uma vez ao ano, no qual a Tabela 5 demonstra os valores.

Tabela 5 - Custo Manutenção Telhado Convencional (Fibrocimento)

\begin{tabular}{|c|c|c|c|c|c|c|c|}
\hline Classe/Tipo & Código & Descrição & Un. & Coef. & Preço & Preço & Preço \\
\hline $\begin{array}{l}\text { 01.sedi.limp.014/ } \\
01\end{array}$ & 99814 & $\begin{array}{l}\text { Limpeza de superfície com jato de } \\
\text { alta pressão. af_04/2019 }\end{array}$ & $\mathrm{m}^{2}$ & & Uni & $\mathrm{m}^{2}$ & $\begin{array}{c}\text { Total } \\
{\left[450 \mathrm{~m}^{2}\right]}\end{array}$ \\
\hline Composição & 88316 & $\begin{array}{c}\text { servente com encargos } \\
\text { complementares }\end{array}$ & $\mathrm{H}$ & 0,089 & 16,54 & 1,47 & 662,43 \\
\hline Composição & 99833 & $\begin{array}{l}\text { Lavadora de alta pressão (lava-jato) } \\
\text { para água fria, pressão de operação } \\
\text { entre } 1400 \text { e } 1900 \text { lib/pol2, vazão } \\
\text { máxima entre } 400 \text { e } 700 \text { I/h - chp } \\
\text { diurno. af_04/2019 }\end{array}$ & $\mathrm{CHP}$ & 0,015 & 1,13 & 0,02 & 7,73 \\
\hline & & Total & & & & & 670,05 \\
\hline
\end{tabular}

Fonte: Adaptado de SINAPI (2019).

Para Oberndorfer et al. (2007), as coberturas vegetadas do tipo extensiva possuem mínima necessidade de manutenção. Nas pesquisas feitas com as empresas a manutenção foi recomendada uma vez ao ano e somente com o intuito de averiguação e retirada de alguma vegetação invasora, seu custo foi retirado do SINAPI no item 98519 e está demonstrado no Tabela 6.

Tabela 6 - Custo Manutenção da Cobertura Vegetada

\begin{tabular}{|c|c|c|c|c|c|c|c|}
\hline Classe/Tipo & Código & Descrição & Un. & Coef. & Preço & Preço & Preço \\
\hline $\begin{array}{l}\text { 02, urba, } \\
\text { pais, } \\
017 / 01\end{array}$ & 98519 & $\begin{array}{l}\text { Revolvimento e limpeza manual de solo, } \\
\qquad \text { af_05/2018 }\end{array}$ & $\mathrm{m}^{2}$ & & Uni & $\mathrm{m}^{2}$ & $\begin{array}{c}\text { Total } \\
{[450} \\
\left.\mathrm{m}^{2}\right]\end{array}$ \\
\hline Composição & 88316 & servente com encargos complementares & $\mathrm{H}$ & 0,0759 & 16,54 & 1,25 & 564,92 \\
\hline Composição & 88441 & jardineiro com encargos complementares & $\mathrm{H}$ & 0,019 & 21,48 & 0,41 & 183,65 \\
\hline \multicolumn{7}{|c|}{ Total } & 748,58 \\
\hline
\end{tabular}

Fonte: Adaptado do SINAPI (2019).

Após o término do orçamento dos custos das coberturas e do resultado das simulações numéricas com informações sobre o consumo de energia elétrica com resfriamento, foi elaborado o fluxo de caixa anual, cujos valores estão expressos na Tabela 7. Ela demonstra o Fluxo de caixa anual para o sistema de cobertura vegetada (C.V.), comparado com a cobertura convencional (C.C.) nas três situações propostas.

Tabela 7 - Fluxo de caixa anual - R\$

\begin{tabular}{cccc}
\hline & Situação A & Situação B & Situação C \\
\hline Consumo Energia C. C. & $24.146,41$ & $24.146,41$ & $24.146,41$ \\
Consumo Energia C. V. & $(22.053,28)$ & $(22.548,55)$ & $(23.208,98)$ \\
Manutenção C.C. & 670,05 & 402,03 & 134,01 \\
Manutenção C.V. & $(748,58)$ & $(449,15)$ & $(149,72)$ \\
\hline Fluxo de caixa anual & $2.014,61$ & $1.550,75$ & 921,73 \\
\hline
\end{tabular}

Nota: Situação $A=$ todas as zonas vegetadas; Situação $B=$ zonas 4, 5, 6 e 7 vegetadas; Situação $C=$ zona 7 vegetada.

Fonte: elaborada pelos autores (2019). 
A partir do fluxo de caixa anual e do valor do investimento inicial foi possível calcular o fluxo de caixa descontado (FCD) e chegar ao resultado do VPL no décimo segundo ano, como demonstrado na Tabela 8.

Tabela 8 - Fluxo de Caixa Descontado - R\$

\begin{tabular}{ccccccc}
\hline & \multicolumn{2}{c}{ Situação A } & \multicolumn{2}{c}{ Situação B } & \multicolumn{2}{c}{ Situação A } \\
\hline Período & FCD & VPL & FCD & VPL & FCD & VPL \\
0 & -53361.72 & -53361.72 & -32017.03 & -32017.03 & -10672.34 & -10672.34 \\
1 & 1901.54 & -51460.17 & 1463.71 & -30553.32 & 870.00 & -9802.35 \\
2 & 1794.82 & -49665.35 & 1381.57 & -29171.75 & 821.17 & -8981.18 \\
3 & 1694.09 & -47971.26 & 1304.03 & -27867.72 & 775.08 & -8206.09 \\
4 & 1599.02 & -46372.24 & 1230.85 & -26636.87 & 731.58 & -7474.51 \\
5 & 1509.28 & -44862.96 & 1161.77 & -25475.11 & 690.53 & -6783.98 \\
6 & 1424.57 & -43438.39 & 1096.57 & -24378.54 & 651.77 & -6132.21 \\
7 & 1344.62 & -42093.77 & 1035.02 & -23343.52 & 615.19 & -5517.02 \\
8 & 1269.16 & -40824.61 & 976.94 & -22366.58 & 580.67 & -4936.35 \\
9 & 1197.93 & -39626.68 & 922.11 & -21444.47 & 548.08 & -4388.27 \\
10 & 1130.70 & -38495.98 & 870.36 & -20574.11 & 517.32 & -3870.96 \\
11 & 1067.24 & -37428.74 & 821.51 & -19752.60 & 488.29 & -3382.67 \\
\hline 12 & 1007.35 & -36421.40 & 775.41 & -18977.20 & 460.88 & -2921.79 \\
\hline
\end{tabular}

Fonte: elaborada pelos autores (2019).

Conforme a Tabela 8, para todas as situações propostas, o fluxo de caixa descontado no período estipulado como limite tem seu valor reduzido aproximadamente a $50 \%$ do inicial. Para que o investimento inicial fosse completamente recuperado, ou seja, ter seu VPL zerado na data limite ainda faltaria recuperar 68\%, $59 \%$ e $27 \%$ do investimento nas situações A, B e $C$ respectivamente.

A Tabela 9 evidencia os métodos VPL, TIR e Payback em comparação nas três situações. Ao décimo segundo ano, final da vida útil da impermeabilização, conforme NBR 15.575-1 (ABNT, 2013), todos os VPL foram negativos, ou seja, em nenhuma das situações propostas o investimento seria totalmente recuperado. $O$ valor do investimento inicial do projeto, nas situações B e C é proporcional a área de cobertura vegetada, porém, a economia de energia com ar condicionado não.

Tabela 9 - Comparativo VPL, TIR e Payback

\begin{tabular}{ccccc}
\hline Proposta & VPL & TIR & Payback & Payback Descontado \\
\hline Situação A & $-36.421,40$ & $-10,50 \%$ & 26,5 & - \\
Situação B & $-18.977,20$ & $-7,50 \%$ & 20,6 & - \\
Situação C & $-2.921,79$ & $0,55 \%$ & 11,6 & 21 \\
\hline
\end{tabular}

Fonte: elaborada pelos autores (2019).

Para Mendes et al. (2005), a simulação computacional proporciona um apoio a tomada de decisão pois permite analisar dados em determinadas situações propostas. Através das simulações pode-se perceber que a utilização da cobertura vegetada oportuniza melhores resultados. As taxas internas de retorno encontradas não superaram a TMA, porém, através da TIR, investimentos iniciais diferentes podem ser comparados diretamente. Para os cenários propostos nesta pesquisa, caso a instituição opte por investir em uma cobertura vegetada por motivos sócio ambientais, a escolha da posição deles tem influência direta na economia de energia com resfriamento. 


\subsection{Análise dos resultados}

Através das análises das cargas térmicas necessárias para resfriamento, constatou-se que dependendo da orientação solar da zona, bem como da carga interna gerada, a cobertura vegetada terá uma porcentagem diferente de redução da carga interna de resfriamento na comparação com a fibrocimento. A zona central teve uma redução na carga térmica de resfriamento de $25,7 \%$, seguida pelas zonas com fachadas orientadas a sul com redução entre 4,0\% e 4,5\%. Enquanto nas zonas a norte a redução variou de $2,0 \%$ a 2,8\%. A redução do consumo de energia elétrica do uso da cobertura vegetada com a de fibrocimento na situação A foi de $6,8 \%$ enquanto a redução financeira foi de $8,7 \%$, esta diferença ocorreu devido ao horário de ponta e fora de ponta terem custos distintos. Devido a diferença de redução na carga térmica de resfriamento entre as zonas, proporcionalmente a área vegetada, a situação $B$ e $C$ tem uma redução mais expressiva. Esta comparação fica traduzida nos valores dos fluxos de caixa descontados, onde mesmo em todos os cenários os VLPs resultem em um valor negativo, na situação $A, B$ e $C$, dentro do período proposto, o investimento seria recuperado parcialmente em $32 \%, 41 \%$ e $73 \%$ respectivamente.

O método da TIR, também evidencia que os investimentos não se recuperam, para a situação $A$ e $B$ ela é negativa em $10,5 \%$ e $7,5 \%$ respectivamente. Para a situação C a TIR é positiva em $0,55 \%$, porém continua sendo inferior a TMA estabelecida indicando que o projeto não deve ser aceito. Para o método do Payback simples, a situação $C$ foi a única que recuperaria o investimento antes de doze anos, mas quando considerada TMA e calculado Payback descontado este passa a ser de 21 anos. Numa situação hipotética do mercado da construção civil, onde ocorresse a redução do preço de uma cobertura vegetada em $44 \%$ (situação A), 38\% (situação B) e 17\% (situação C), seria possível, no tempo previsto, recuperar o investimento.

\section{CONCLUSÃO}

Este artigo buscou verificar a viabilidade econômica e financeira entre o uso de cobertura vegetada e convencional para uma edificação educacional pública em Florianópolis. $\mathrm{O}$ trabalho propôs analisar 4 modelos, sendo uma cobertura padrão, uma totalmente vegetada e 2 mistas, através da simulação computacional pelo software EnergyPlus. Para chegar ao comparativo foi elaborado um modelo do último pavimento de uma instituição educacional e determinado seu tipo de uso, bem como as cargas internas consideradas no estudo.

Conforme demonstrado na análise dos resultados a cobertura vegetada, nas 3 situações propostas, apresentou VPL negativo, payback simples maior que o tempo de vida útil considerado para limitar o estudo e em todos os casos a TIR foi inferior a TMA. De acordo com a situação atual de mercado, o estudo não foi viável economicamente, entretanto apresenta inúmeros benefícios difíceis de mensurar financeiramente.

Entretanto, além da melhora no desempenho térmico do ambiente interno, a cobertura vegetada diminui o escoamento superficial de águas pluviais, diminui o efeito de ilhas de calor, melhora a qualidade do ar e colabora com a preservação da biodiversidade por espécies que o utilizam como espaço de vivência ou como corredor ecológico. Tais benefícios contribuem para proporcionar cidades e sociedades mais sustentáveis.

Sendo assim, por não se tratar de uma tecnologia cuja finalidade é somente de vantagem financeira, e assim optar-se conscientemente por esse investimento com intuito de promover uma redução no consumo energético e proporcionar outros benefícios sociais e ambientais, seu estudo prévio pode otimizar economicamente este investimento.

Este trabalho apresenta limitações, como uso em ocupação limitada a uso educacional (aulas, manhã, tarde e noite), em período do ano letivo, com carga interna específica, para o clima de Florianópolis. Outra limitação é a comparação feita entre a cobertura vegetada e fibrocimento. Como sugestão para futuras pesquisas indica-se comparação com outros tipos de coberturas convencionais, pois possuem propriedades térmicas distintas, além da comparação com custos diferentes e o emprego de outros indicadores econômicos financeiros para análise da viabilidade. 


\section{REFERÊNCIAS}

ABEL, David de Campos et al. Análise da viabilidade econômico-financeira da implantação de energia solar fotovoltaica no Hotel Praiano (Tapes/RS). In: Encontro Internacional sobre Gestão Ambiental e Meio Ambiente, 21., 2019, São Paulo. São Paulo: Anais Engema, 2019. p. 1-11. Disponível em: http://engemausp.submissao.com.br/21/anais/arquivos/214.pdf. Acesso em: 10 set. 2020.

ABNT - ASSOCIAÇÃO BRASILEIRA DE NORMAS TÉCNICAS. NBR 15.220-2: Desempenho térmico de edificações - Parte 2: Métodos de cálculo da transmitância térmica, da capacidade térmica, do atraso térmico e do fator solar de elementos e componentes de edificações. Rio de Janeiro, 2005ª.

ABNT - ASSOCIAÇÃO BRASILEIRA DE NORMAS TÉCNICAS. NBR 15.575-1: Edificações Habitacionais Desempenho. Parte 1: Requisitos Gerais. Rio de Janeiro, 2013.

ABNT - ASSOCIAÇÃO BRASILEIRA DE NORMAS TÉCNICAS. NBR 15.575-5: Edificações Habitacionais Desempenho. Parte 1: Requisitos para sistemas de coberturas. Rio de Janeiro, 2013.

ABNT - ASSOCIAÇÃO BRASILEIRA DE NORMAS TÉCNICAS. NBR 16401-2: Instalações de ar-condicionado Sistemas centrais e unitários - Parte 2: Parâmetros de conforto térmico. Rio de Janeiro, 2008.

AGOPYAN, V.; JOHN, V.M. O desafio da Sustentabilidade na Construção Civil. São Paulo: Blucher, 2011.

ANEEL. Postos Tarifários. Disponível em: http://www.aneel.gov.br/postos-tarifarios Acesso: 25 abr. 2019.

BAETA, A. P. Orçamento e Controle de Preços de Obras Públicas. São Paulo: Pini, 2012.

BALANÇO ENERGÉTICO ANUAL, 2018. Disponível em: http://epe.gov.br/sites-pt/publicacoes-dadosabertos/publicacoes/PublicacoesArquivos/publicacao-377/topico-

494/BEN\%202019\%20Completo\%20WEB.pdf. Acesso em: 12 dez 2019;

BORDEAUX-RêGO, R. et al. Viabilidade Econômico-Financeira de Projetos. Rio de Janeiro: FGV, 2010.

BRASIL. Decreto n 25.899, de 24 de março de 2015. Regulamenta O Art. $5^{\circ}$ da Lei № 8.474 , de 02 de outubro de 2013, e Institui O Programa de Certificação Sustentável "IPTU Verde" em Edificações no Município de Salvador, Que Estabelece Benefícios Fiscais Aos Participantes do Programa, Assim Como O Art. $5^{\circ}$ da Lei № 8.723, de 22 de Dezembro de 2014, e Dá Outras Providências. Salvador. Disponível em: https://leismunicipais.com.br/a/ba/s/salvador/decreto/2015/2589/25899/decreto-n-25899-2015regulamenta-o-art-5-da-lei-n-8474-de-02-de-outubro-de-2013-e-institui-o-programa-de-certificacaosustentavel-iptu-verde-em-edificacoes-no-municipio-de-salvador-que-estabelece-beneficios-fiscais-aosparticipantes-do-programa-assim-como-o-art-5-da-lei-n-8-723-de-22-de-dezembro-de-2014-e-da-outrasprovidencias Acesso em: 3 set 2018.

BRASIL. Instrução Normativa 02, de 04 de junho de 2014. Dispõe sobre regras para a aquisição ou locação de máquinas e aparelhos consumidores de energia pela Administração Pública Federal direta, autárquica e fundacional, e uso da Etiqueta Nacional de Conservação de Energia (ENCE) nos projetos e respectivas edificações públicas federais novas ou que recebam retrofit. Disponível em:

https://www.comprasgovernamentais.gov.br/index.php/legislacao/instrucoes-normativas/304-instrucaonormativa-n-2-de-04-de-junho-de-2014. Acesso em: 3 set. 2018.

BRASIL. Lei 18.112, de 12 de janeiro de 2015. Dispõe sobre a melhoria da qualidade ambiental das edificações por meio da obrigatoriedade de instalação do "telhado verde", e construção de reservatórios de acúmulo ou de retardo do escoamento das águas pluviais para a rede de drenagem e dá outras providências. Disponível em: http://www.normasbrasil.com.br/norma/lei-18112-2015-recife_280138.html. Acesso em: 2 set. 2018. 
CLIMATE ONE BUILDING. Arquivo Precipitação Florianópolis. Disponível em: http://climate.onebuilding.org/WMO_Region_3_South_America/BRA_Brazil/index.html. Acesso em: 07 abr. 2019.

CAPOZZOLI A.; GORRINO A.; CORRADO V. Thermal characterization of green roofs through dynamic simulation. In: CONFERENCE OF INTERNATIONAL BUILDING PERFORMANCE SIMULATION, 13., 2013, França. Proceedings [...] França: [s.n.], 2013.

CELESC. Tarifas. Disponível em: http://www.celesc.com.br/portal/index.php/duvidas-mais-frequentes/ 1140tarifa?fbclid=IwAR1 kd-TBXjHuiqqor8eQ-yX2CHfpeqGaqEHWexNM2eQr4ehtIVwqcc9pcto Acesso em: 27 abr. 2019.

COSTA, L. M. O.; LIMA, F. R. S. Economia de energia com ar condicionado proporcionada por telhados verdes e refletivos em diferentes climas do brasil. Encac: ELACAC, Balneário Camboriú, p.1547-1556, set. 2017.

DALFOVO, Wylmor Constantino Tives et al. A Viabilidade Econômica da implantação de Energia Solar Fotovoltaica para a redução dos custos com energia elétrica das famílias com diferentes níveis de renda: uma análise para a região norte de Mato Grosso. Sociedade, Contabilidade e Gestão, Rio de Janeiro, v. 14, n. 3, p. 118-143, set. 2019.

DASSI, Jonatan Antonio et al. Análise da viabilidade econômico-financeira da energia solar fotovoltaica em uma Instituição de Ensino Superior do Sul do Brasil In: CONGRESSO BRASILEIRO DE CUSTOS, 22., 2015, Foz do Iguaçu. Anais XXII Congresso Brasileiro de Custos Foz do Iguaçu:, 2015. p. 1-16.

DELBONO, B. F.; RODRIGUES, F. S. Os aspectos jurídicos da sustentabilidade na construção civil e a importância do incentivo governamental na utilização de materiais sustentáveis. Congresso Luso Brasileiro de Materiais de Construção Sustentável, p.167-174, mar. 2014.

DIAS, A. E. O desempenho térmico de uma cobertura verde em simulações computacionais em três cidades brasileiras. 2016. 190 f. Dissertação (Mestrado) - Curso de Engenharia Civil, Universidade Federal de Santa Catarina, Florianópolis, 2016.

ELETROBRÁS - Centrais Elétricas Brasileiras S. A., PROCEL - Programa Nacional de Conservação de Energia Elétrica. Pesquisa de Posse de equipamentos e Hábitos de Uso - Ano base 2005 - Casse Comercial Instituições de Ensino - Relatório Brasil. Rio de Janeiro, 2007.

FERRAZ, I. L. O desempenho térmico de um sistema de cobertura verde em comparação ao sistema tradicional de cobertura com telha cerâmica. Dissertação (Mestrado) - Escola Politécnica da Universidade de São Paulo. São Paulo - SP, 2012.

FREZATTI, Fábio. Gestão da Viabilidade Econômico-Financeira dos Projetos de Investimento. São Paulo: Atlas, 2008.

GABC. 2019 Global Status Report for Buildings and Construction. United Nations Environment Programme: IEA, 2019.

GIL, A. C. Como Elaborar Projetos de Pesquisa. São Paulo: Atlas, 2002.

INMETRO. Tabela de eficiência energética. Disponível em: http://www.inmetro.gov.br/consumidor/pbe/condicionadores_ar_split_hiwall_indicenovo.pdf. Acesso em: 17 abr. 2019.

INSTITUTO NACIONAL DE METROLOGIA, NORMALIZAÇÃO E QUALIDADE INDUSTRIAL. RTQ-C: Regulamento Técnico da Qualidade para o Nível de Eficiência Energética de Edificações Comerciais, de Serviços e Públicas. Rio de Janeiro: Procel Edifica, 2010. 
IPEA. Sustentabilidade ambiental no Brasil: biodiversidade, economia e bem-estar humano. Brasília: Governo Federal, 2010.640 p.

KLEIN, L. B. Controle qualitativo e quantitativo do escoamento pluvial em diferentes tipos de cobertura. 2017. 181 f. Dissertação (Mestrado) - Curso de Engenharia Civil, Universidade Federal de Santa Catarina, Florianópolis, 2017.

KREUZ, Carlos Leomar et al. Custos de produção, expectativas de retorno e de riscos do agronegócio da uva na região dos Campos de Palmas. Revista Alcance, Itajaí, v.11, n.2. p. 239-258, maio/ago. 2004. Disponível em: https://siaiap32.univali.br/seer/index.php/ra/article/view/1807/1435 Acesso em: 10 set. 2020.

KUMAR, V. V.; MAHALLE, A. M. Investigation of the thermal performance of green roof on a mild warm climate. International Journal of Renewable Energy Research, v. 6, n. 2, p. 487-493, 2016

LAMBERTS, R.; DUTRA, L.; PEREIRA, F. O. R. Eficiência Energética na Arquitetura. 3. ed. Florianópolis: ELETROBRAS/PROCEL, 2014.

LAPPONI, Juan Carlos. Projetos de investimento na empresa. Rio de Janeiro: Elsevier, 2007. 322 p.

LIZ, D. G. S. Análise experimental do comportamento térmico do telhado verde extensivo para Florianópolis. 2016. 111 f. Dissertação (Mestrado) - Curso de Arquitetura e Urbanismo, Universidade Federal de Santa Catarina, Florianópolis, 2016.

LUCHEZZI, C. Logística Reversa na Construção Civil. São Paulo: Haryon, 2017

MACHADO, A. F. et al. Telhado verde: uma alternativa sustentável para o século XXI. Synergismus Scyentifica Utfpr, Pato Branco, v. 12, n. 1, p.176-182, nov. 2017.

MARTINELLI, Gabrielli do Carmo et al. Viabilidade econômica de sistema de aquaponia, no município de são josé dos pinhais, paraná. In: ENCONTRO INTERNACIONAL SOBRE GESTÃO AMBIENTAL E MEIO AMBIENTE, 21. 2019, São Paulo. Anais Engema. São Paulo: 2019. p. 1-17. Disponível em:

http://engemausp.submissao.com.br/21/anais/arquivos/383.pdf. Acesso em: 10 set. 2020.

MENDES, Nathan et al. Uso de Instrumentos Computacionais Para Análise do Desempenho Térmico e Energético de Edificações no Brasil. Ambiente Construído, Porto Alegre, v. 5, n. 4, p. 47-68, out./dez. 2005.

MINGUET, J. M. The New Ecological Home: Materials for bioclimatic design. Barcelona: Monsa, 2016.143 p.

OBERNDORFER, E. et al. Green Roofs as Urban Ecosystems: Ecological Structures, Functions, and Services. Bioscience, v. 57, n.10, p.823-833, 2007. Oxford University Press (OUP). DOI:10.1641/b571005.

ORGANIZAÇÕES DAS NAÇÕES UNIDAS. Objetivo 7. Assegurar o acesso confiável, sustentável, moderno e a preço acessível à energia para todas e todos. Disponível em https://nacoesunidas.org/pos2015/ods7/ Acesso em: 3 set. 2018.

PASSAGLIA, R. C.; SANTOS, C. A. F.; GUIDINI, W. P. Análise de investimento para geração de energia elétrica através do biogás em uma propriedade de suínos. In: ENCONTRO INTERNACIONAL SOBRE GESTÃO AMBIENTAL E MEIO AMBIENTE, 21., 2019, São Paulo. Anais Engema. São Paulo: USP, 2019. p. 1-11. Disponível em: http://engemausp.submissao.com.br/21/anais/arquivos/268.pdf. Acesso em: 10 set. 2020.

PEREIRA, M. F. B. Conteúdo energético e emissões de co2 em coberturas verdes, de telha cerâmica e de fibrocimento: estudo de caso. Dissertação (Mestrado) - Universidade Federal de Santa Maria, Santa Maria RS, 2014.

PROCEL. Manual de Tarifação da Energia Elétrica. Rio de Janeiro: Eletrobras, 2011. 
PROJETEE. Componentes construtivos. Disponível em: http://projeteee.mma.gov.br/componentesconstrutivos/\#pisos-e-coberturas. Acesso em: 10 out. 2018.

RAZZAGHMANESH, M.; BEECHAM, S.; SALEMI, T. The role of green roofs in mitigating Urban Heat Island effects in the metropolitan area of Adelaide, South Australia. Urban Forestry \& Urban Greening, [s.l.], v. 15, p. 89-102, 2016.

RECEITA FEDERAL. Taxa de Juros Selic. Disponível em:

https://receita.economia.gov.br/orientacao/tributaria/pagamentos-e-parcelamentos/taxa-de-juros-selic. Acesso em: 10 set. 2020.

SAADATIAN, O. et al. A review of energy aspects of green roofs. Renewable And Sustainable Energy Reviews, [s.l.], v. 23, p. 155-168, jul. 2013.

SAILOR, D. J. A green roof model for building energy simulation programs. Energy And Buildings, v. 40, n. 8, p.1466-1478, jan. 2008.

SANTOS, T. C. S. S. Organizações da sociedade civil e as construções teóricas contemporâneas acerca da sustentabilidade. Revista do Centro Interdisciplinar de Desenvolvimento e Gestão Social, Salvador, v.2, n.1, p. 105-120, dez. 2009.

SILVEIRA, R.; MARINOSKI, D. L.; LAMBERTS, R. Avaliação da absortância à radiação solar e temperatura superficial de telhas de fibrocimento utilizadas nas coberturas de edificações do campus da UFSC. In: ENCONTRO NACIONAL DE TECNOLOGIA DO AMBIENTE CONSTRUÍDO, 14., 2012, Juiz de Fora. Anais Entac, Juiz de Fora: UFJF, 2012. p.1166-1170.

SINAPI, Insumos e Composições. Disponível em: http://www.caixa.gov.br/poder-publico/apoio-poderpublico/sinapi/insumos-composicoes/Paginas/default.aspx. Acesso em: 10 maio 2019.

SOUZA JÚNIOR, Alberto Jorge et al. Energia solar em organizações militares: uma análise da viabilidade econômico-financeira. Navus, Florianópolis, v. 9, n. 1, p. 63-73, mar. 2019. Disponível em: http://navus.sc.senac.br/index.php/navus/article/view/762/pdf. Acesso em: 10 set. 2020.

SYDNEY. Green Roofs and Walls Policy Implementation Plan. Sidney, Austrália: Green Global Connectd, 2014.

YEMAL, J. A.; TEIXEIRA, N. O. V.; NAAS, I. A. Sustentabilidade na construção civil. In: INTERNATIONAL WORKSHOP ADVANCES IN CLEANER PRODUCTION, 3., 2011. São Paulo. Anais International workshop advances in cleaner production. São Paulo: Intertox, 2011. p. 1-10. 